Proceedings

\title{
Snowfall Events as a Factor of Snow Cover Stratigraphy Formation ${ }^{+}$
}

\author{
Vladimir N. Golubev, Marina N. Petrushina and Denis M. Frolov* \\ Geographical Faculty, Lomonosov Moscow State University, Moscow 119991, Russia; golubev@geol.msu.ru \\ * Correspondence: denisfrolovm@mail.ru; Tel.: +7-903-617-2536 \\ + Presented at the 2nd International Electronic Conference on Atmospheric Sciences, 16-31 July 2017; \\ Available online: http://sciforum.net/conference/ecas2017.
}

Published: 17 July 2017

\begin{abstract}
Snowfall events are considered as a factor of spatial distribution of snow cover thickness, its snow water equivalent and stratigraphy formation. Under the term of snowfall it is understood an event of solid atmospheric precipitation (snow) with duration of certain period of time (up to one or several days) with intensity of not less than $0.1 \mathrm{~mm}$ per day and the temperature below zero, i.e. under condition of snow cover presence. Snowfalls' intensity is characterized as a sum of precipitation (its snow water equivalent) during this snowfall. For the time period of 1960-2016 on the basis of meteorological data for 45 stations situated on the territory of Russia (not less than two in each of 19 climatic regions) the events of snowfalls are determined, as well as their frequency and averaged intensity for each winter season. Snowfalls' spatial and temporal distribution is analyzed on the basis of the compiled maps of averaged frequency (number per season) of all snowfalls and snowfalls of defined intensity $(0.1-2.5,2.5-5,5-10,10-20$ and more than $20 \mathrm{~mm})$. The materials of obtained distribution allow revealing the features in distribution of snowfalls of different intensity for the various regions and the possibility to model generalized regional stratigraphy of snow cover.
\end{abstract}

Keywords: snowfalls' frequency; snowfalls' intensity; snow cover stratigraphy

\section{Introduction}

Previous works [1-3] have demonstrated interannual variability in the intensity and occurrence of snowfalls in different regions of the USA and Europe, although some long-term trends in these characteristics were revealed as well. In our previous work [4] snowfall-events are considered as a factor of formation of snow-cover distribution (inhomogeneity of snow cover thickness) on the territory of Russia, its snow water equivalent and its stratigraphy.

In present work it is continued to apply presented in [4] methodic for characterization of regional stratigraphy and snow water equivalent of snow cover on the base of meteorological data. In this methodic in particular assumed, that formation of the different snow layers in snow thickness is the result of separate snowfalls (as well as thaws, strong winds etc.) and the number and water equivalent of snow layers correspond to the number and water equivalent of snowfalls of winter season.

\section{Experiments}

For the reason of consideration of snowfalls as a factor of stratigraphy formation the term of 'snowfall' is referred as an event of solid atmospheric precipitation (snow) with duration of certain period of time (up to one or several days) with intensity of not less than $0.1 \mathrm{~mm}$ per day and temperature below zero, i.e., under condition of snow cover presence. Snowfalls' intensity is characterized as a sum of precipitation (its snow water equivalent) during this snowfall. For the time 
period of 1960-2016 on the basis of meteorological data for 45 stations situated on the territory of Russia (not less than two in each of 19 climatic regions) the events of snowfalls are determined, as well as theirs frequency (number per season) and averaged intensity for each winter season (November-March).

The total number of snowfalls per winter season as well as number of snowfalls of the defined intensity $(0.1-2.5,2.5-5,5-10,10-20$ and more than $20 \mathrm{~mm})$ are revealed for interval of 1960-2016. Such classification criterion of snowfalls intensity is taken on the base of [5] and is used for the wide range of applied problems and forecasts. However other classification criteria exist (like in [6]).

The real snow stratigraphy in different geosystems (forest, field) in Moscow region were observed during the recent years. In general, the number of snow layers can be the same in different geosystems but their thickness and properties can differ.

\section{Results}

The maps of frequency (number per season) of all snowfalls and snowfalls of defined intensity $(0.1-2.5,2.5-5,5-10,10-20$ and more than $20 \mathrm{~mm})$ for the averaged winter season for the period of 1960-2016 have been compiled on the base of obtained data on the number of snowfalls of defined intensity.

The tendency of variation from the areas with predominance of the snowfalls with low intensity (0.1-2.5 mm) (Central and North-East Yakutia) (up to 26 snowfalls per season) (light areas on the Figure 1a) towards the areas with predominance of the snowfalls with medium intensity (2.5-5 and 5-10 mm (up to 5-8 and 4 snowfalls per season correspondingly) at European territory of Russia and on the coasts of Bering, Okhotsk and Japan seas) (dark areas on the Figure 1b,c) has been revealed on the maps of spatial distribution of the snowfalls' number of defined intensity for the averaged winter season.

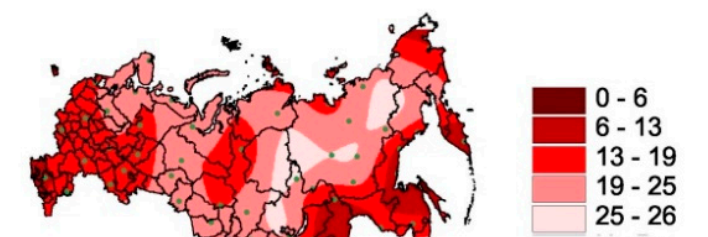

(a)
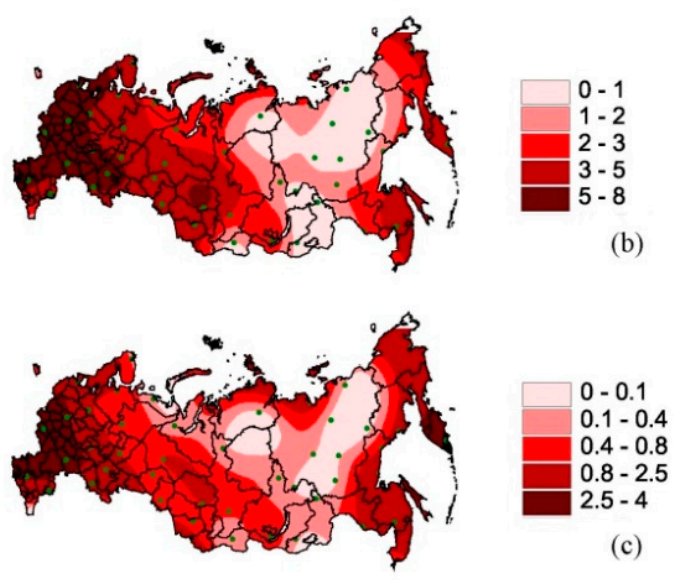

(b)

(c)

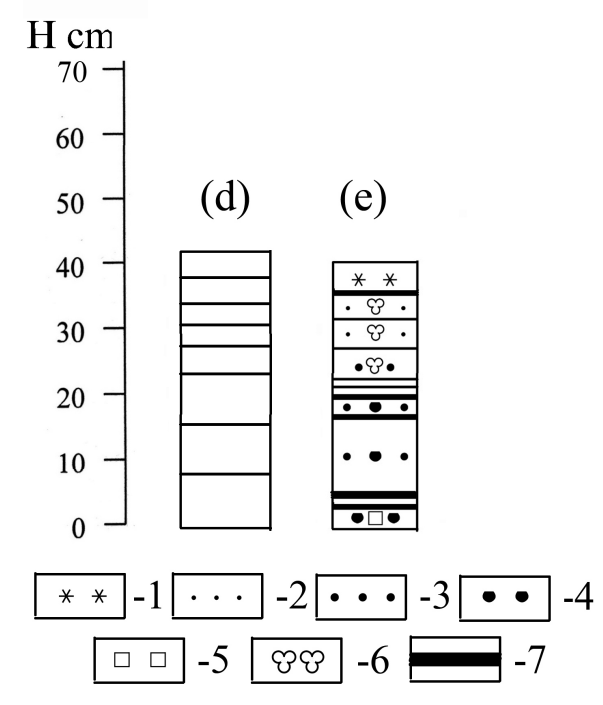

Figure 1. Number of snowfalls for the averaged winter period with intensity: (a) 0.1-2.5 mm; (b) 2.5$5 \mathrm{~mm}$; (c) 5-10 mm. Moscow region stratigraphic columns for the maximum of snow accumulation: (d) modeled, generalized-averaged for winter seasons 1960-2016; (e) real observations for winter season 2014/15. Snow stratigraphy notation: (1) new snow; (2) fine-grained snow; (3) medium-grained snow; (4) coarse-grained snow; (5) faceted crystals; (6) refrozen ice crystals; (7) ice crust. 
The generalized regional stratigraphy of snow cover on the base of these maps has been modeled. The number of the layers with the defined water equivalent value (which was determined on the base of intensity of corresponding snowfalls) and thickness of these layers in this generalized regional stratigraphy were calculated on base of information on the number of snowfalls of determined intensity for the winter season and mean value of snow density in this region. For example, mean snow density value of the snow cover for the considered time period in Moscow region is $0.24 \mathrm{~g} / \mathrm{cm}^{2}$ and $0.17 \mathrm{~g} / \mathrm{cm}^{2}$ in Yakutsk region according to [7].

So, the total number of snowfalls for the generalized averaged winter season 1960-2016 in Moscow region is 26 , where 16 snowfalls have intensity $0-2.5 \mathrm{~mm}, 7$ snowfalls $-2.5-5 \mathrm{~mm}$ and 2-3 snowfalls with intensity of $5-10 \mathrm{~mm}$. Therefore it is expected to find in the stratigraphic column of snow cover 2-3 layers with snow water equivalent (s.w.e.) $5-10 \mathrm{~mm}$, up to 7 layers with s.w.e. 2.5-5 $\mathrm{mm}$ and up to 16 layers of s.w.e. $0.1-2.5 \mathrm{~mm}$. The layers of s.w.e. $0.1-2.5 \mathrm{~mm}$ may merge with the more massive layers or just be invisible in generalized averaged winter season snow stratigraphy (Figure 1d). Some similarity of the modelled stratigraphy for Moscow region can be observed at the real column (Figure 1e) in Moscow. So, for the displayed on the Figure 1e real observation of snow stratigraphy for winter season 2014/15 corresponds 6 snowfalls with intensity $0.1-2.5 \mathrm{~mm}, 3$ snowfalls with intensity $2.5-5 \mathrm{~mm}, 2$ snowfalls with intensity $5-10 \mathrm{~mm}, 4$ snowfalls with intensity $10-20 \mathrm{~mm}$ and 2 snowfalls with intensity more than $20 \mathrm{~mm}$. The presence of more heavy snowfalls in recent years than in long-term average period is caused partly by general growth of precipitation amount during the considered time period in Moscow region. The difference of the modeled and the real stratigrphy can mainly be explained by the fact that not all events (such as thaws, strong wind and so on) were taken into account.

\section{Conclusions}

On the base of the introduced in [4] methodic and algorithm of snowfalls' determination the snowfalls frequency (number per season) and intensity for the winter 1960-2016 are revealed. The maps of distribution of averaged for the considered time-period number of snowfalls of the defined intensity (0.1-2.5, 2.5-5, 5-10, 10-20 and more than $20 \mathrm{~mm}$ ) are compiled. The modelled generalized regional stratigraphy of snow cover has a good verification with really observed snow cover stratigraphy for Moscow region.

Acknowledgments: The study is partly supported by Russian Fund of Basic Research; grant N 15-05-04461.

Author Contributions: V.N.G. and M.N.P. conceived and designed the modeling methodic; D.M.F. performed the calculations; V.N.G., M.N.P. and D.M.F. analyzed the data and wrote the paper.

Conflicts of Interest: The authors declare no conflict of interest. The founding sponsors had no role in the design of the study; in the collection, analyses, or interpretation of data; in the writing of the manuscript, and in the decision to publish the results.

\section{Abbreviation}

The following abbreviation are used in this manuscript:

s.w.e. Snow Water Equivalent

\section{References}

1. Mahoney, J.L. Climatology of snowfall-event characteristics at Denver. In Proceedings of the Western Snow Conference, Juneau, Alaska, 12-15 April 1991.

2. Berger, C.L.; Lupo, A.R.; Browning, P.; Bodner, M.; Chambers, M.D.; Rayburn, C.C. Climatology of northwest Missouri snowfall events: Long-term trends and interannual variability. Phys. Geogr. 2002, 23, $427-448$.

3. Schmidli, J.; Frei, C. Trends of heavy precipitation and wet and dry spells in Switzerland during the 20th century. Int. J. Climatol. 2005, 25, 753-771, doi:10.1002/joc.179. 
4. Golubev, V.N.; Petrushina, M.N.; Frolov, D.M. Winter regime of temperature and precipitation as a factor of snow-cover distribution and its stratigraphy. Ann. Glaciol. 2008, 49, 179-186.

5. Directives on Short-Term Weather Forecast for General Purpose; Ruling Document (RD) 52.27.724-2009; IG-SOCIN: Obninsk, Russia, 2009. (In Russian)

6. Elsevier's Dictionary of Glaciology; Kotlyakov, V.M., Smolyarova, N.A., Eds.; Elsevier: Amsterdam, The Netherlands, 1990; 336p.

7. Specialized Data for Climatic Research. Available online: http://aisori.meteo.ru/ClimateR (accessed on 30 June 2017).

(C) 2017 by the authors. Licensee MDPI, Basel, Switzerland. This article is an open access article distributed under the terms and conditions of the Creative Commons Attribution (CC BY) license (http://creativecommons.org/licenses/by/4.0/). 